\title{
Passive respiratory mechanics: the occlusion techniques
}

\author{
M. Gappa*, A.A. Colin", I. Goetz", J. Stocks"
}

Passive respiratory mechanics: the occlusion techniques. M. Gappa, A.A. Colin, I. Goetz, J. Stocks. (C) ERS Journals Ltd 2001.

ABSTRACT: The aim of this position paper is to define quality control and acceptance criteria for measuring passive respiratory mechanics in infants using the occlusion techniques to ensure that valid results are obtained. These guidelines cover numerous aspects including: 1) terminology and definitions; 2) equipment; 3) data acquisition; 4) data handling and analysis; 5) reporting of results. Adherence to these guidelines should ensure that measurement of passive respiratory mechanics in infants in different lung function laboratories could be performed with an acceptable degree of safety, precision, and reproducibility. This will facilitate multi-centre collection of data and performance of clinical investigations.

Eur Respir J 2001; 17: 141-148.

\begin{abstract}
*University Children's Hospital, Dept Paediatric Pulmonology and Neonatology, Medizinische Hochschule Hannover, Hannover, Germany, "Division of Respiratory Diseases, Children's Hospital, Harvard Medical School, Boston, MA, USA and "Portex Anaesthesia, Intensive Therapy and Respiratory Medicine Unit, Institute of Child Health, London, UK.
\end{abstract}

Correspondence: M. Gappa, University Children's Hospital, Dept Paediatric Pulmonology and Neonatology, Medizinische Hochschule Hannover, D30623 Hannover, Germany. Fax: 495115329125

Keywords: Infant, occlusion techniques, passive respiratory mechanics, respiratory function tests, respiratory mechanics, standardization

Received: March 102000

Accepted after revision June 142000

This work was supported by a grant from the European Respiratory Society, and by donations from Glaxo-Wellcome (UK) and GlaxoWellcome AB (Sweden).
This document represents one of a series that is being produced by the European Respiratory Society/American Thoracic Society Task Force on standards for infant respiratory function tests. The aim of this Task Force is to summarize what is currently seen to be good laboratory practice, and to provide recommendations for both users and manufacturers of infant lung function equipment and software. These recommendations have been developed after widespread communication on an international level and are directed towards future developments in this field, including the use of more automated and standardized equipment than has been used in many clinical and research centres in the past.

It is important to emphasize that the recommendations presented here do not invalidate previously published data collected with less automated systems or without all the quality control that has now been suggested. It is recognized that this document will need regular update in response to advances in both

Previous articles in this series: No. 1: U. Frey, J. Stocks, A. Coates, P.D. Sly, J. Bates, on behalf of the ERS/ATS Task Force on Standards for Infant Respiratory Function Testing. Specifications for equipment used for infants pulmonary function testing. Eur Respir J 2000; 16: 729-738. No. 2: P.D. Sly, R. Tepper, M. Henschen, M. Gappa, J. Stocks, on behalf of the ERS/ATS Task Force on Standards for Infant Respiratory Function Testing. Tidal forced expirations. Eur Respir J 2000; 16: 739-746. No. 3: U. Frey, J. Stocks, P. Sly, J. Bates, on behalf of the ERS/ATS Task Force on Standards for Infant Respiratory Function Testing. Specifications for signal processing and data handling uses for infant pulmonary function testing. Eur Respir J 2000; 16: 1016-1022. No. 4: J.H.T. Bates, G. Schmalisch, D. Filbrun, J. Stocks, on behalf of the ERS/ATS Task Force on Standards for Infant Respiratory Function Testing. Tidal breath analysis for infant pulmonary function testing. Eur Respir J 2000; 16: $1180-1192$. 
technology and knowledge regarding the application and interpretation of these tests under different circumstances. In the meantime, every attempt has been made to avoid being too prescriptive to allow for future developments, while at the same time offering guidance as to minimum standards for those developing equipment and performing tests. Acceptance and application of these recommendations could be of particular value when attempting to compare data between centres, develop or use reference data. In addition, with increasing emphasis on the need for multi-centre trials if meaningful conclusions are to be reached when using parameters of infant respiratory function as outcome measures, they could provide an essential platform from which to develop the necessary standardized protocols.

Passive respiratory mechanics including compliance, resistance and the expiratory time constant of the respiratory system have been assessed using a variety of closely related methods. This document will concentrate on the two most commonly used methods, (i.e. the single breath technique (SBT), here referred to as single occlusion technique (SOT) to distinguish it from the terminology used in gas washout techniques)) [1-3] and the multiple occlusion technique (MOT) $[4,5]$. Other techniques for measuring passive mechanics include the multiple interrupter technique, expiratory volume clamping and weighted spirometry, which have been reviewed recently [6] but have not gained broad acceptance. Measurements of passive mechanics in the intensive care setting [7] and dynamic lung mechanics using oesophageal manometry [8] will be considered in subsequent documents. The theoretical background and practical details of how to apply the MOT and SOT, together with a consideration of factors that may influence the measurements and interpretation of results have been described previously $[6,9,10]$ and will not be repeated here. A discussion of the clinical applications or usefulness of measuring passive respiratory mechanics in infants is beyond the scope of this paper. However, it should be noted that whereas the value of assessing infant lung function as an outcome measure in clinical or epidemiological research studies is well established, the use of such tests in individual infants as diagnostic or therapeutic measures, remains far more controversial $[6,9]$.

Careful use of the equipment to ensure patient safety remains the responsibility of the operator. Routine safety measures when performing any type of infant lung function measurement include: 1) full resuscitation equipment, including suction, being available at the site of infant lung function testing plus a suitable alarm system; 2) two individuals (other than parents) being present during testing, one of whom has prime responsibility for the infant's well being; the infant must never be left unattended; 3) continuous monitoring (and ideally recording) using at least pulse oximetry; 4) transparent face mask for monitoring of the infant; and 5) adherence to the hospital specific protocol for sedation or anaesthesia. Further details regarding measurement conditions which may influence infant safety or the accuracy and reproducibility of results have been published previously [10]. Accompanying papers in this series also provide full details regarding specifications for equipment and software when assessing respiratory function in infants $[11,12]$.

\section{Terminology and definitions}

The MOT and SOT can be used in spontaneously breathing infants to assess passive mechanics of the total respiratory system (i.e. lung + chest wall) noninvasively in the absence of all respiratory muscle activity. Total respiratory system compliance $(C \mathrm{rs})$ is a measure of the combined elastic recoil of the lung and chest wall. Resistance of the respiratory system ( $R \mathrm{rs})$ represents the sum of airways, lung tissue and chest wall resistance. Reference to measurements obtained using pressure changes at the airway opening as airway, lung, pulmonary or thoracic resistance is misleading, and adherence to the referenced terminology is recommended to avoid confusion.

The airway occlusion techniques for assessing passive respiratory mechanics are based on the ability to invoke the Hering Breuer Inflation Reflex (HBIR) in infants and young children [13, 14]. Provided rapid equilibration can be reached during periods of no flow, the relaxation pressure at the airway opening $(P$ ao $)$ represents alveolar pressure, which in turn represents the summed elastic recoil pressure of the lung and chest wall during periods of muscle relaxation. This pressure $(P)$ can be related to changes in volume $(V)$ and flow $\left(V^{\prime}\right)$ in order to calculate the compliance $(V / P)$ and resistance $\left(P / V^{\prime}\right)$ of the respiratory system.

For the SOT, the airway opening is occluded at the end of a tidal inspiration (fig. 1). Provided the HBIR

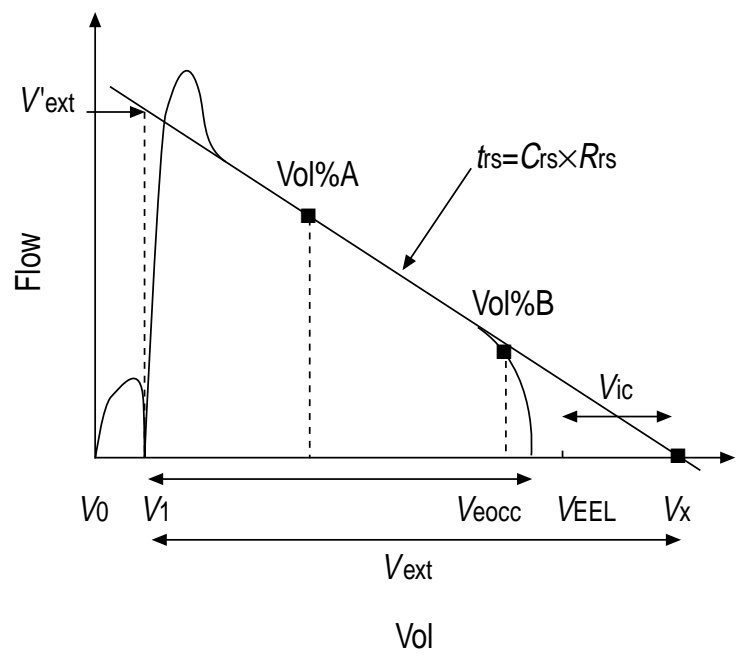

Fig. 1. - Flow-volume-curve obtained following end inspiratory occlusion for the single occlusion technique. $V^{\prime}$ ext: extrapolated flow; $V$ ext: extrapolated volume; $V_{0}$ : volume at start of expiration; $V_{1}$ : volume at time of occlusion; $t$ rs: expiratory time start for respiratory system; $C$ rs: compliance; $R$ rs: resistance; Vol\%A: volume remaining in the lung at the start of the regression, expressed as a percentage of the expired volume from release of the occlusion to end of expiration; $\mathrm{Vol} \% \mathrm{~B}$ : expired volume at the end of the portion of the F/V slope selected for regression, expressed as a percentage of the expired volume from release of the occlusion to that at the end of expiration; $V_{\mathrm{x}}$ : intersection of $t \mathrm{rs}$ with volume axis; VEEL: mean of last 5 end-expiratory lung volumes; Veocc: volume at end of expiration following release of occlusion; $V_{\text {ic: }}$ volume intercept (difference between $V_{\mathrm{x}}$ and $V_{\text {eocc) }}$. 


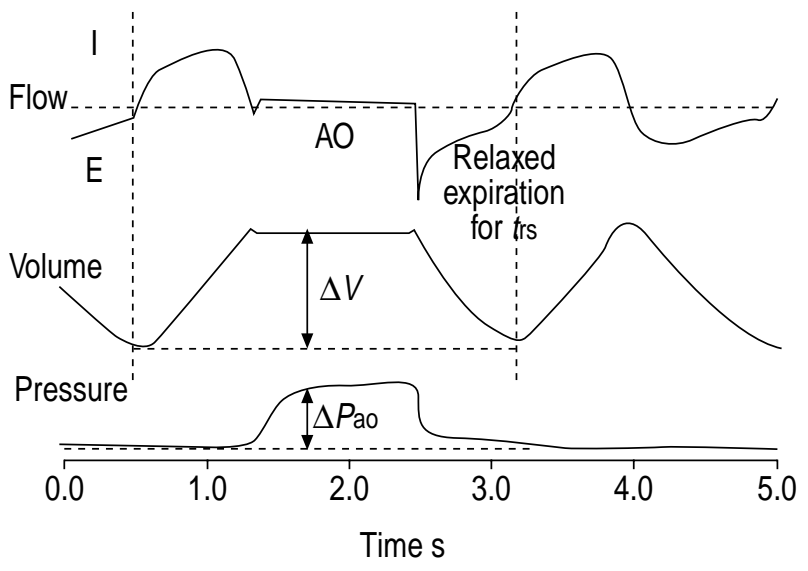

Fig. 2. - End-inspiratory airway occlusion as performed during the single or multiple occlusion techniques. $\Delta V$ : change in volume during breath; $\Delta P$ ao: change in airway opening pressure; $t \mathrm{rs}$ : expiratory time constant for respiratory system; AO: airway occlusion; I: inspiration; E: expiration.

is invoked by temporarily maintaining lung volume above the end expiratory volume, the time based pressure trace develops a plateau, which represents elastic recoil pressure. Similarly, provided expiration remains relaxed when the occlusion is released, and a single compartment can represent the respiratory system, the descending portion of the volume-flow loop presents a straight line (fig. 2). The slope of this straight line represents the expiratory time constant of the respiratory system $(t \mathrm{rs})$, which is the time required for lung volume to decrease passively by $63 \%$. The intersection of the extrapolated $t$ rs with the volume axis $\left(V_{\mathrm{x}}\right)$ indicates the volume to which the infant would have expired had expiration not been interrupted by an inspiratory effort (i.e. the elastic equilibrium volume (EEV) of the respiratory system). The volume in the lung at the time of the occlusion ( $V_{1}$ on fig. 1$)$ above this EEV is calculated as $V_{\mathrm{ext}}=\left(V_{1}-V_{\mathrm{x}}\right)$. The ratio of change in $V$ to that of $P$ represents respiratory compliance and hence:

$$
C_{\mathrm{rs}}=\frac{\Delta V_{\mathrm{ext}}}{\Delta P_{\mathrm{oa}}}
$$

Since $t r$ rs represents the product of $R$ rs and $C$ rs, resistance can be calculated as:

$$
R_{\mathrm{rs}}=\frac{t \mathrm{rs}}{C_{\mathrm{rs}}}
$$

Alternatively $R$ rs can be calculated directly by extrapolating the $t$ rs to measure pseudoflow at the moment of occlusion ( $V^{\prime}$ ext) and relating this to the prevailing elastic recoil pressure:

$$
R_{\mathrm{rs}}=\Delta P_{\mathrm{ao}} / \Delta V^{\prime} \mathrm{ext}
$$

Whichever approach is used the apparatus resistance must be subtracted before reporting the result (see below).
For the MOT, airway occlusions are performed several times at different points of expiration. Provided the HBIR is invoked, the time based $P$ trace presents a plateau that represents the elastic recoil pressure at the moment of the occlusion $(P 1, P 2$, etc $)$. If the corresponding $V$ above functional residual capacity remaining in the lung at the time of occlusion $\left(V_{1}, V_{2}\right.$, etc) is then plotted against $P 1, P 2$, etc, the slope of the resulting $V-P$ plot, which is calculated by linear regression, will represent $C$ rs, and the intercept on the volume axis the extent to which end-expiratory lung volume is being dynamically elevated. Thus, for assessment of passive respiratory mechanics, accurate recordings of $V, V$ and $P$ are necessary.

\section{Equipment}

Further details on general equipment and software requirements for infant lung function testing have been published elsewhere [11, 12]. In general: 1) the combined apparatus resistance should not exceed; $1.2 \mathrm{kPa} \cdot \mathrm{L}^{-1} \cdot \mathrm{s}$ at $50 \mathrm{~mL} \cdot \mathrm{s}^{-1}$ in spontaneously breathing preterm infants; $0.7 \mathrm{kPa} \cdot \mathrm{L}^{-1} \cdot \mathrm{s}$ at $100 \mathrm{~mL} \cdot \mathrm{s}^{-1}$ in term neonates; $0.5 \mathrm{kPa} \cdot \mathrm{L}^{-1} \cdot \mathrm{s}$ at $300 \mathrm{~mL} \cdot \mathrm{s}^{-1}$ in infants and young children; 2 ) the combined apparatus dead space (excluding the mask) should not exceed $1.5-2 \mathrm{~mL} \cdot \mathrm{kg}^{-1}$.

\section{Face mask}

The brand and size of face mask should be reported and dead space should be minimized (for example by using silicone putty).

\section{Flowmeter}

This should be a low resistance, low dead space device, with a linear range appropriate for the age and size of the infant studied and the flows likely to be encountered. As in the previous documents published in this series, the flowmeter will generally be referred to as a pneumotachometer (PNT), since this is currently the most commonly used flow measuring device. However, anemometers and ultrasonic flowmeters may prove to be equally applicable in the future. If a PNT or other device subject to errors due to condensation is used, it should always be heated to body temperature. Every system needs to be checked to ensure that the PNT is perfectly balanced and that pressurization of the PNT during an occlusion will not influence the $V^{\prime}-V$ data obtained [15].

The ranges of flow likely to be encountered during the occlusion techniques are summarized in table 1. It should be noted that flow transients can occur after

Table 1. - Flow ranges of pneumotachometers recommended for use with infants of various masses

\begin{tabular}{lc}
\hline $\begin{array}{l}\text { Infant mass } \\
\mathrm{kg}\end{array}$ & $\begin{array}{c}\text { Flow range } \\
\mathrm{mL} \cdot \mathrm{s}^{-1}\end{array}$ \\
\hline$<2$ & $0-200$ \\
$2-4$ & $0-300$ \\
$4-10$ & $0-600$ \\
$>10$ & $0-1000$ \\
\hline
\end{tabular}


release of the occlusion during the SOT (release of compressed air/rapid emptying of upper airways), which may exceed the ranges quoted for basal tidal breathing at any given age/weight range. It is particularly important to ensure that adequate flow resolution [11] (see section Measurement protocol) and breath detection algorithms are used when testing preterm infants and neonates where mean $V$ may be $<30 \mathrm{~mL} \cdot \mathrm{s}^{-1}$ $[16,17]$.

\section{Pressure transducers}

The pressure range likely to be encountered with a flow transducer is $\pm 0.2 \mathrm{kPa}$ if a PNT is used. The $P$ ao range likely to be encountered is $\pm 2 \mathrm{kPa}$, unless used in ventilated infants, where $P$ s may be higher. A pressure transducer that is linear to $\pm 5 \mathrm{kPa}$ is adequate for both circumstances.

\section{Occlusion valves}

A shutter/valve to occlude the airway opening with a pressure port and appropriate connectors to the face mask and PNT is required. Any valve directly connected to the patient's airway must default to the open position. An electronic switch that can be activated manually by the operator to open the valve to the airway opening should be included. Ideally, to avoid pressurization of the PNT during occlusion, the valve should be positioned between the face mask and PNT, although this is not essential if the system is perfectly balanced [15]. If using the SOT in a ventilated infant on an intensive care unit, there is wide agreement that the shutter should open to atmosphere. Otherwise the mechanical properties of the ventilator circuit will be included in the calculation. The disadvantage of expiration to atmosphere is that information regarding the end expiratory level will be lost unless a second PNT is introduced in the set-up. In addition, the loss of positive end expiratory pressure (PEEP) during such measurements may have adverse clinical implications. There is no current consensus as to the best approach in these circumstances [7]. The valve should have the following characteristics: 1) it should be designed with minimal dead space and apparatus resistance (see above) [11]; 2) activation of the valve should produce no or minimal noise to avoid disturbing the infant; and 3 ) the shutter must be leak-free and able to hold $P$ s up to at least $2 \mathrm{kPa}$ for use with the occlusion techniques in a spontaneously breathing infant, or up to $4 \mathrm{kPa}$ when used in a ventilator circuit.

\section{Monitor display}

1) For safety reasons, tidal volume $(V \mathrm{~T})$ and/or $V^{\prime}$ should be monitored at all times while the mask is applied. Additional monitoring of $P$ ao is optional depending on the equipment used. 2) During data collection and/or replay, a simultaneous display of time based traces for $V^{\prime}, V, P$ ao and $V^{\prime}-V$ curves are required, to assist in recognition of the stability of breathing pattern and absence of leaks. 3) A separate expanded time based display of $P$ ao is required to allow evaluation of the pressure plateau with respect to equilibrium, relaxation and evidence of any leak (fig. 2). 4) During on-line analysis, acceptable breaths/manoeuvres should be displayed on screen according to the technique used. 5) A further window should display either the $V^{\prime}-V$ plot (SOT) or a cumulative plot of the $V-P$ data (MOT), with a final window summarizing the results. 6) For the MOT, it is useful to display the $V$-P plot indicating how many successful occlusions have been performed, with automatic calculation of $C$ rs once at least five acceptable occlusions have been performed. The ability to toggle between the time based trace and the corresponding point on the $V-P$ plot is essential. 7) To assist quality control and manual checking of results displayed, factors such as the amplitude, duration and variability of the pressure plateau and the stability of the end expiratory level (EEL) should be tabulated.

\section{Data acquisition}

\section{Sampling}

Data acquisition requirements are in keeping with those described previously [11, 12]. In summary: 1) recommended sampling rate is $200 \mathrm{~Hz}$, although in slowly breathing older infants, a rate of $100 \mathrm{~Hz}$ will suffice when only measuring the MOT; 2) inspired $V^{\prime}$ and $V$ should be converted to body temperature, pressure, and saturated (BTPS) conditions; this can be performed at driver level in an attempt to minimize drift during data collection or during replay prior to presentation of results; 3) any drift of the $V \mathrm{~T}$ signal prior to occlusions should be minimized; and 4) a representative end expiratory level must be established (see Analysis section).

\section{Measurement protocol}

General procedures. The general principles of infant respiratory testing, including the importance of standardizing measurement conditions and the use of sedation have been discussed previously [10]. In general: 1) the infant should be lying supine with the neck and/or shoulders supported in the midline in slight extension. The position should be stabilized by using neck roll or head ring. If an alternative posture is used this should be stated clearly in any publication; 2) attach face mask, using a thin ring of silicone putty to achieve mask seal if desired); 3) check mask seal by performing an occlusion test [18]. To do this, record tidal breathing for approximately $30 \mathrm{~s}$, followed by a high-volume (end-inspiratory) occlusion and at least 5 breaths following the occlusion to allow stabilization of the EEL. Loss of $P$ ao during the occlusion and/or a step up in $V$ following release of the occlusion usually indicates a leak around the face mask (or tracheal tube). This will be indicated by the percentage change in EEL $(\mathrm{d} \% \mathrm{EEL})$, which is calculated as: 
$\mathrm{d} \% \mathrm{EEL}=100 \times($ EELpre occlusion - EELpost occlusion $) / V \mathrm{~T}$

Values $>10 \%$ or $1 \mathrm{~mL} \cdot \mathrm{kg}^{-1}$ usually indicate a leak. In this case the mask seal should be adjusted and the occlusion test repeated. 4) Flow through the PNT during the occlusion may indicate a leak through the occlusion valve (or an inadequately balanced PNT). In this case, try to adjust or recalibrate the PNT. 5) Record approximately $30 \mathrm{~s}$ of tidal breathing prior to the first manoeuvre and repeat later if necessary to provide a measure of resting tidal breathing, stability of EEL and some indication regarding sleep state.

Data collection. An option to accept/discard manoeuvres at time of data collection must be included.

Single occlusion technique. Verify tidal $V^{\prime}-V$ loops are stable (i.e. regular breathing pattern, absence of drift or leaks). Perform a minimum of five technically acceptable end-inspiratory occlusions. Occlusions should occur within $3 \mathrm{~mL}$ (or $5 \%$ of $V \mathrm{~T}$ ) from start of expiration, and should be held for a minimum of $400 \mathrm{~ms}$. The latter is important to ensure that true pressure equilibration has occurred in the majority of infants when using an automated shutter. While default values should be adjustable by experienced users, if this value is set too low there is a real danger of false plateau recognition by any automated system and hence premature opening of the shutter, with loss of potentially useful data. Occlusions should be released after a $P$ ao plateau of $100 \mathrm{~ms}$ has been recorded (a plateau being defined as that period over which maximum change in pressure from start to end is 20 $\mathrm{Pa}$, with a SD of $<10 \mathrm{~Pa}$ ), or a maximum of $1,500 \mathrm{~ms}$ have elapsed. If an infant fails to relax upon airway occlusion (i.e. continuing rise of $P$ ao) the valve should be released after a maximal occlusion time of 1,500 $\mathrm{ms}$ or as soon as any inspiratory effort against the closed valve is detected (i.e. negative pressure swing). The breath is suitable for further analysis if expiration is relaxed and continues to the previously established EEL $\left( \pm 1 \mathrm{~mL} \cdot \mathrm{kg}^{-1}\right)$, if not data collection should continue.

Multiple occlusion technique. 1) Perform a minimum of five end-inspiratory or early expiratory occlusions. Occlusions should occur within $3 \mathrm{~mL}$ (or $5 \%$ of $V \mathrm{~T}$ ) from start of expiration. 2) Occlusions should be held for a minimum of 400 and maximum of $1,500 \mathrm{~ms}$ to ensure adequate time for equilibration. This time can vary greatly even within an individual infant on the same occasion. 3) Occlusions should be released once the $P$ ao plateau is stable over at least $100 \mathrm{~ms}$ (a plateau being defined as that period over which maximum change in pressure from start to end is $20 \mathrm{~Pa}$, with a SD of $<10 \mathrm{~Pa}$ ). 4) A plateau duration of at least $200 \mathrm{~ms}$ gives greater confidence in complete relaxation and is easily achieved in older infants and when the respiratory rate is $<50 \mathrm{~min}^{-1}$. However, in rapidly breathing infants, and during the SOT where it is more crucial to release the occlusion as soon as possible if a complete expiration is to be achieved, $100 \mathrm{~ms}$ should suffice. Hence, the duration of the plateau can be set to $100 \mathrm{~ms}$ by default, but needs to be adaptable by the user. 5) At least 10 breaths should elapse between occlusions to allow stabilization of the EEL. In infants with a low respiratory rate and stable EEL it may be sufficient to allow slightly fewer breaths between occlusions to avoid undue prolongation of the measurement. 6) Ideally, an automated occlusion valve would be programmed to trigger at different predefined intervals during the expiration. 7) Continue until on-line analysis of the $V$ - $P$ data gives at least 10 technically satisfactory occlusions over a pressure range of $>0.4 \mathrm{kPa}$ and a value of $C$ rs with $r^{2}>0.95$. 8) If the infant wakes up before data collection is complete, or if the EEL is unstable, it may be necessary to repeat the entire sequence of data collection for MOT in order to minimize the spread of data on the $V-P$ scatter plot. 9) Optional: once data collection for MOT is complete, inspect data from end-inspiratory occlusions to assess whether any are also suitable for analysis using the SOT (see Criteria for technically acceptable data section).

\section{Analysis}

The ability to exclude (but not delete) manoeuvres during final analysis is required. Definitions are calculations required are shown in table 2 .

A weight corrected display of $V \mathrm{~T}, V$ ic and $C$ rs is very helpful during on line analysis, but this ratio should not be calculated for $R$ rs where the relationship between $R$ rs and body weight is neither linear nor passes close to the origin. No infant respiratory function test parameters should ever be expressed per $\mathrm{cm}$ body length for the same reason.

\section{Quality control parameters}

Parameters to determine quality of end expiratory level. EELs (mL): SD of EEL - measured relative to the baseline EEL calculated over 5 breaths prior to each occlusion manoeuvre after drift correction of the volume signal; EELs\%: stability of EEL prior to the occlusion, i.e EELs expressed as a percentage of the $V \mathrm{~T}$ prior to each occlusion manoeuvre: $\mathrm{EELs} \%=100$ $\times$ EELs/VT; $\mathrm{d} \% \mathrm{EEL}(\%)$ : change in EEL (end expiratory level) post-pre occlusion after drift correction, expressed as percentage of mean $V$ T prior to occlusion $(V \mathrm{~T})$, calculated as ( $V$ EEL,pre-occ - $V$ EEL,post-occ $) /$ $V \mathrm{~T}) \times 100$.

Pre-occlusion value is the mean EEL over the last five breaths before the occlusion. Post-occlusion value is the mean EEL of 3-4 breaths once this has stabilized after release of the occlusion. Since this may take several breaths to occur, the initial breaths should be ignored when making this calculation. Thus, if 10 breaths are recorded after releasing the occlusion in order to allow the EEL to restabilize, then the EEL should be based on that from breaths 8,9 and 10 post-occlusion. This parameter can only be calculated if there are at least five breaths before and after the occlusion.

Parameters to assess adequacy of pressure plateau. tocc (ms): duration of occlusion; tplat (ms): length of plateau during occlusion; $P$ ao-s $(\mathrm{Pa})$ : standard deviation of 
Table 2. - Definitions and calculations

\begin{tabular}{|c|c|}
\hline Parameter & Definition \\
\hline$V \mathrm{~T} \mathrm{~mL}$ & Mean tidal volume of at least 5 breaths prior to occlusion \\
\hline $\mathrm{RR} \min ^{-1}$ & Mean respiratory rate of at least 5 breaths prior to the occlusion calculated as (60/total breath time) \\
\hline$P$ ao $\mathrm{kPa}$ & $\begin{array}{l}\text { Mean pressure at the airway opening over the plateau obtained during airway occlusion. During the } \\
\text { MOT, multiple measures of } P \text { ao will be obtained }(P 1, P 2, \text { etc })\end{array}$ \\
\hline$V$ EEL $\mathrm{mL}$ & $\begin{array}{l}\text { Mean volume at baseline end expiratory level from previous } 5 \text { breaths, after the baseline has been } \\
\text { adjusted for any drift }\end{array}$ \\
\hline$V_{\text {occ }} \mathrm{mL}$ & $\begin{array}{l}\text { Difference between the mean end expiratory level ( } V \mathrm{EEL}) \text { prior to the occlusion and the volume } \\
\text { during the occlusion (calculated as } V 1-V \mathrm{EEL}) \text {. The volume during the occlusion is taken as the mean } \\
\text { overall samples from } 50-200 \mathrm{~ms} \text { after start of occlusion. Labelled as } V \text { occ, } 1,2, \ldots \text { n to relate to } \\
\text { corresponding } P 1, P 2, \ldots \text { n data when applying the MOT (figs. } 2 \text { and } 3 \text { ) }\end{array}$ \\
\hline$V 1 \mathrm{~mL}$ & $\begin{array}{l}\text { Volume in the lung at time of occlusion }(V \text { occ- } V \text { EEL); see figure } 2 . \text { The number represents the volume } \\
\text { at serial occlusions. Thus } 1=\text { volume at first occlusion and so forth }\end{array}$ \\
\hline$V$ ext $\mathrm{mL}$ & $\begin{array}{l}\text { Extrapolated volume, i.e. the volume in the lung at time of occlusion above the elastic equilibrium } \\
\text { volume }\end{array}$ \\
\hline$V$ icSO mL & $\begin{array}{l}\text { Volume intercept for the SOT. The volume difference between } V \mathrm{x} \text { and mean } V \text { EEL prior to the } \\
\text { occlusion, calculated as } V \text { EEL- } V \text { x. Note: } V \text { ic is calculated with respect to the mean EEL prior to } \\
\text { airway occlusion and not to the actual EEL from the occluded breath since infants frequently inspire } \\
\text { early following release of occlusion (fig. 1). NB. volume intercept must not be negative and is } \\
\text { generally }<3 \mathrm{~mL} \cdot \mathrm{kg}^{-1}\end{array}$ \\
\hline $\mathrm{r}^{2} \mathrm{SO}$ & $\begin{array}{l}\text { Coefficient of determination for linear regression of } t \text { rs over the selected portion of the descending } \\
\text { expiratory flow/volume loop. Regression should encompass at least } 40 \% \text { of expiration, start }<65 \% \\
\text { and extend to within at least } 15 \% \text { of end expiration. The suggested default for regression would be } \\
\text { between } 55 \text { to } 5 \% \text { of volume remaining in the lung during expiration (fig. 1) }\end{array}$ \\
\hline CrsSO $\mathrm{mL} \cdot \mathrm{kPa}^{-1}$ & Respiratory system compliance measured with the single occlusion technique calculated as $\left(V_{\mathrm{ext}} / P_{1}\right)$ \\
\hline $\operatorname{trsSO~s}$ & $\begin{array}{l}\text { Time constant of the respiratory system calculated by linear regression of the relaxed descending } \\
\text { portion of the expiratory flow/volume curve }(\operatorname{trs}=V / V=C \mathrm{rs} \times R \mathrm{rs})\end{array}$ \\
\hline$R$ app $\mathrm{kPa} \cdot \mathrm{L}^{-1} \cdot \mathrm{s}^{-1}$ & Resistance of the apparatus calculated as $P / V^{\prime}$ at mid-flow point from $t$ rs analysis \\
\hline $\operatorname{RrsSO} \mathrm{kPa} \cdot \mathrm{L}^{-1} \cdot \mathrm{s}^{-1}$ & Respiratory system resistance derived from the single occlusion technique as $R \mathrm{rs}=\left(t_{\mathrm{rs}} / C \mathrm{rs}\right)-R$ app \\
\hline GrsSO L $\cdot \mathrm{s}^{-1} \cdot \mathrm{kPa}^{-1}$ & $\begin{array}{l}\text { Respiratory system conductance (the reciprocal of resistance }(1 / R \mathrm{rs}) \text { derived from the single occlusion } \\
\text { technique }\end{array}$ \\
\hline$V^{\prime}$ ext $\mathrm{mL} \cdot \mathrm{s}^{-1}$ & Pseudoflow at moment of occlusion, calculated by backward extrapolation of the $t$ rs \\
\hline CrsMO $\mathrm{mL} \cdot \mathrm{kPa}^{-1}$ & $\begin{array}{l}\text { Respiratory system compliance measured with the multiple occlusion technique as the regression of } \\
\text { volume on pressure from acceptable occlusions }\end{array}$ \\
\hline$V$ icMO mL & $\begin{array}{l}\text { Volume intercept from MOT is the volume where the slope of the resulting volume-pressure plot } \\
\text { crosses the volume axis (fig. 3) }\end{array}$ \\
\hline $\mathrm{r}^{2} \mathrm{MO}$ & Coefficient of determination for $V / P$ regression during MOT \\
\hline
\end{tabular}

plateau pressure during the occlusion; $\mathrm{d} \% P$ ao $(\%): \%$ change in pressure at the airway opening between start and end of plateau phase.

Parameters to ensure adequate trs. $\mathrm{r}^{2}$ : Coefficient of determination; VicSO: Volume intercept.

\section{Criteria for technically acceptable data}

Single occlusion technique. 1) Smooth expiration, proceeding to within $10 \%$ of previous expiration, and without evidence of glottic closure, braking or active expiratory efforts. 2) Duration $P 1 \geqslant 100 \mathrm{~ms}$ and variability $<10 \mathrm{~Pa}$. 3) Linearity of $V^{\prime}-V$ curve over at least $40 \%$ of expiration with $r^{2}>0.99$. Breaths meeting these acceptance criteria should be stored; the mean, SD and/or coefficient of variation for $C$ rs-SO, $R$ rs-SO and $t$ rs should be calculated from up to 5 (minimum 3 ) technically acceptable manoeuvres. If MOT is performed simultaneously, $C_{\text {rs-SO should fall within }}$ $95 \%$ confidence interval of $C$ rs-MO [19].

Multiple occlusion technique. d $\%$ EEL: $<10 \% ; P 1$, P2 etc: $\mathrm{d} \% P$ ao $<2 \%$ and $P$ ao-s SD $<10 \mathrm{kPa}$ over at least $100 \mathrm{~ms}$; $\mathrm{r}^{2}$ for $V I P>0.95$; $\mathrm{n}$,occ: minimum of $\mathrm{n}=6$ satisfactory occlusions, over a range of $\geqslant 0.4 \mathrm{kPa}$.

\section{Reporting}

Major outcome variables

Routine report for clinical studies; parameters may vary according to which technique has been applied: 1)

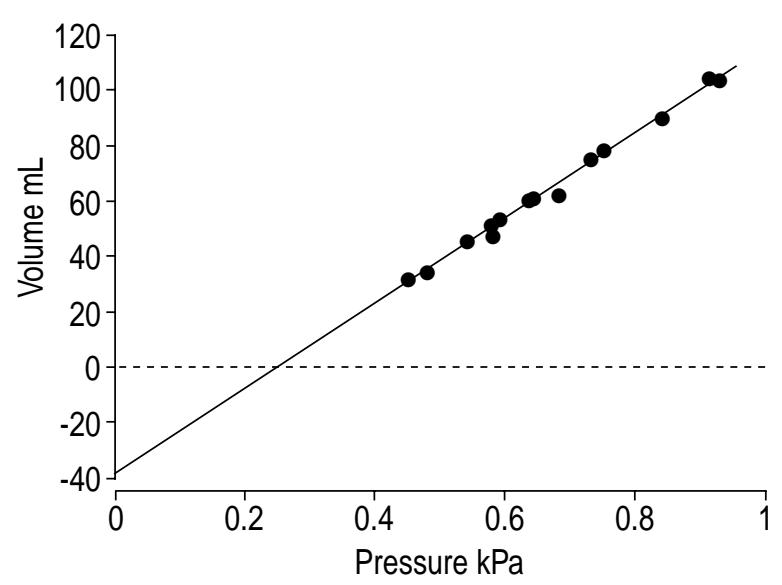

Fig. 3. - Volume-pressure plot as obtained from the multiple occlusion technique. 
Mean $C$ rsSo, $t$ rsSo, and $R$ rsSo; 2) $C$ rsMo; 3 ) Print out of a representative SO curve; and 4) Print out of $V$ - $P$ plot with the regression line (MO).

\section{Quality control parameters to be stored with data or reported if indicated}

1) $\mathrm{r}^{2}$, coefficient of variation $((\mathrm{sD} /$ mean $) \times 100)$, and $95 \%$ confidence intervals as appropriate according to parameters measured. 2) Number of acceptable occlusions (SOT and MOT separately). 3) Total number of occlusions performed. 4) Apparatus dead space and resistance. 5) Type of mask. 6) Mean tidal volume prior to occlusions. 7) Mean respiratory rate at the beginning of data collection. 8) Stability of EEL at the beginning of data collection.

\section{Reference data}

For MOT and SOT, only limited data from healthy infants, mostly neonates and healthy preterm infants, are available. Because there have been no standards for equipment, published data from healthy infants are laboratory specific and should be interpreted with caution.

For the MOT, data on 283 infants with an age range of one day to 60 weeks have been reported with $C$ rsMO ranging from $9.1 \mathrm{~mL} \cdot \mathrm{kPa}^{-1} \cdot \mathrm{kg}^{-1}$ body weight to 16.2 $\mathrm{mL} \cdot \mathrm{kPa}^{-1} \cdot \mathrm{kg}^{-1}$ body weight. Similarly, for the SOT, published normal data in 54 infants with an age range from one day to 24 months, ranged 12.2-15.1 $\mathrm{mL} \cdot \mathrm{kPa}^{-1} \cdot \mathrm{kg}^{-1}$ body weight $[6,20]$.

Respiratory system resistance is very variable with higher volumes in preterm infants and those studied during the first few months of life than during later infancy. An upper limit of normality at any given age or body size has still to be established. The challenges that need to be addressed when establishing reliable reference data for infant respiratory function tests have been discussed recently [9, 12]. For practical purposes: 1) data should be reported in relation to the "normal range" rather than as "percent of predicted"; 2) once appropriate reference values are available, respiratory system compliance, respiratory system resistance and the expiratory time constant of the respiratory system could be reported as $Z$ scores; 3 ) if participating in multicentre trials, each individual laboratory will need to ensure that appropriate reference data are available for their population and that their equipment produces appropriate values on the Standard Equipment Assessment System that is currently being developed by the Task Force.

Acknowledgements. The authors would like to thank all other members of the Task Force who contributed to developing these recommendations: J. Allan (Philadelphia, PA, USA), J.H.T. Bates (Montreal, Canada). E. BarYishay (Jerusalem, Israel), C. Beardsmore (Leicester, UK), R. Castile (Colombus, OH, USA), J.B. Clough (Southampton, UK), A.L. Coates (Toronto, Canada), I. Dundas (London, UK), D. Filbrun (Colombus, OH, USA), U.
Frey (Berne, Switzerland), S. Godfrey (Jerusalem, Israel), P. Gustafsson (Skövde, Sweden), R. Gregson (Southampton, UK), M. Henschen (Freiburg, Germany), A-F. Hoo (London, UK), A. Jackson (Boston, MA, USA), J. de Jongste (Rotterdam, The Netherlands), R. Kraemer (Berne, Switzerland), S. Lum (London, UK), P. Merkus (Rotterdam, The Netherlands), I.T. Merth (Leiden, The Netherlands), M. Morris. (Little Rock, AR, USA), B. Reinmann (Berne, Switzerland), G. Schmalisch (Berlin, Germany), P. Seddon (Brighton, UK), G. Sharma (Chicago, IL, USA), M. Silverman (Leicester, UK), P.D. Sly (West Perth, Western Australia), R. Tepper, (Indianapolis, IN, USA), D. Vilozni (Petach-Tikva, Israel), E. van der Wiel (Rotterdam, The Netherlands), and to all those around the world, including members of the industry, who read the various drafts and provided valuable feedback.

\section{References}

1. Mortola JP, Saetta M. Measurements of respiratory mechanics in the newborn: a simple approach. Pediatr Pulmonol 1987; 3: 123-130.

2. Le Souëf PN, England SJ, Bryan AC. Passive respiratory mechanics in newborns and children. $\mathrm{Am}$ Rev Respir Dis 1984; 129: 552-556.

3. Thomson AH, Beardsmore CS, Silverman M. The total compliance of the respiratory system during the first year of life. Bull Eur Physiopathol Respir 1985; 21 : 411-416.

4. Olinsky A, Bryan AC, Bryan MH. A simple method of measuring total respiratory system compliance in newborn infants. S Afr Med J 1976; 50: 128-130.

5. Thomson A, Silverman M. Single-breath measurement of lung mechanics in very low birth weight infants. Crit Care Med 1985; 13: 4-8.

6. Fletcher ME, Baraldi E, Steinbrugger B. Passive Respiratory Mechanics. In: Stocks J, Sly PD, Tepper RS, Morgan WJ, eds. Infant Respiratory Function Testing. New York: John Wiley \& Sons, Inc., 1996; pp. 283-328.

7. Sly PD, Lanteri C, Nicolai T. Measurement of respiratory function in the intensive care unit. In: Stocks J, Sly PD, Tepper RS, Morgan WJ, eds. Infant Respiratory Function Testing. New York, John Wiley \& Sons, Inc., 1996; pp. 445-484.

8. Coates AL, Stocks J. Esophageal pressure manometry in human infants. Pediatr Pulmonol 1991; 11: 350360.

9. Stocks J, Sly PD, Tepper RS, Morgan WJ, eds. Infant Respiratory Function Testing. 1st ed. New York, Wiley-Liss, Inc.; 1996.

10. Gaultier C, Fletcher ME, Beardsmore C, England S, Motoyama E. Respiratory function measurements in infants: measurement conditions. Eur Respir J 1995; 8: 1057-1066.

11. Frey U, Stocks J, Coates A, Sly P, Bates J. Standards for infant respiratory function testing: Specifications for equipment used for infant pulmonary function testing. Eur Respir $J$ 2000; 16: 731-740.

12. Frey U, Stocks J, Sly P, Bates J. Specifications for signal processing and data handling used for infant pulmonary function testing. Eur Respir $J$ 2000; 16: 1016-1022. 
13. Stark AR, Frantz IDI. Prolonged expiratory duration with elevated lung volume in newborn infants. Pediatr Res 1979; 13: 261-264.

14. Rabbette PS, Fletcher ME, Dezateux CA, SorianoBrucher H, Stocks J. The Hering-Breuer reflex and respiratory system compliance in the first year of life: a longitudinal study. J Appl Physiol 1994; 76: 650-656.

15. Coates AL, Fletcher ME, Dundas I, Stocks J. The single breath test in neonates: Does pressurization of the pneumotachograph make a difference? Pediatr Pulmonol 1995; 19: 299-306.

16. Schmalisch G, Foitzik B, Wauer RR, Stocks J. In vitro assessment of equipment and software used to assess tidal breathing parameters in infants. Eur Respir $J$ 2001; 17: 100-107.
17. Bates J, Schmalisch G, Filbrun D. Tidal breath analysis for infant pulmonary function testing. Eur Respir J 2001; 16: 1180-1192.

18. Stocks J, Nothen U, Sutherland P, Hatch DJ, Helms P. Improved accuracy of the occlusion technique for assessing total respiratory compliance in infants. Pediatr Pulmonol 1987; 3: 71-77.

19. Gappa M, Rabbette PS, Costeloe KL, Stocks J. Assessment of passive respiratory compliance in healthy preterm infants: A critical evaluation. Pediatr Pulmonol 1993; 15: 304-311.

20. American Thoracic Society/European Respiratory Society. Respiratory mechanics in infants: physiologic evaluation in health and disease. Eur Respir $J$ 1993; 6: 279-310. 